\title{
Application of Critical Path in the Construction Engineering Project
}

\section{Management}

\author{
Du Hengji, a \\ ${ }^{1}$ School of information engineering,Qujing Normal University ,Qujing655011,China \\ aduhengjiqj@126.com
}

Keywords: Critical path; Construction project; Project management; Application

\begin{abstract}
The critical path method is the Internet figure that takes single point of time to assess on the basis of a strict order. The critical path provides great help for construction engineering project management. The critical path, however, was not to conduct a comprehensive solution at this point of scarce resources, and with the load of resources and the demand of technology rise, need shrinking time cycle, which problem become more prominent in recent years. To make the critical path to complete increase critical chain project management construction like engineering project management time, this has gradually been recognized and accepted by public. Application of the critical path can assist construction engineering project to a great extent, especially conduct a graphical display for the construction project and the primary activities, the quantitative information provide the important research basis for clear organization risks, project risk delay, resource risk and risk management.
\end{abstract}

\section{Introduction}

Critical path method is to analyze the different items during project schedule time and least to prediction and optimization of project time limit for a project, construction project management usually has a huge investment, so, about how to integrate in fixed investment limited resources, through the lowest cost and the shortest time to complete the project is the key problem existing in project management, application of critical path in the construction engineering project management, and further correction and optimization of construction engineering project design concept has become very important. [1]Critical path in the design concept in construction project management is mainly in order to be able to in the engineering construction of the Internet to find the critical path, resource priority arrangement for the different key activities, improve subjective initiative, prevent paxson's law, save time, project for non-critical activity, as long as it doesn't affect the project schedule, the remaining resources to deploy, as well as applications of the critical path, easy to save time, make the resource utility get improved.

\section{The problems existing in the construction engineering project management}

In the construction of the current our country enterprise, because most of the construction enterprises still adopts the traditional personnel manual calculation and analysis of traditional project management methods in the field survey and investigation, which is not only time-consuming, also reduce the accuracy of the project decisions. [2]Though, there are also part of the construction enterprises began to apply project management system, but it doesn't full attention to construct the project management application project management system, ignore the system of 
informatization, automation application advantages, make the system cannot help project managers to do a good job of engineering construction project management, reduce the system application benefit. Some engineering construction enterprises in the current development in the process of project management system software, and not according to the actual circumstance of construction engineering project management to develop a system design scheme, makes the actual application of this system for project management and the actual project management occurs deviation, reduce the application performance of the system.

\section{The critical path}

The United States Dupont put forward the critical path in 1956 for the first time; in 1957, the critical path has been applied in the construction of chemical plants of \$10 million, 4 months shorter period compared with the original plan. The United States dupont during the application of critical path, save $\$ 1$ million a year. And what is the critical path, this study first to introduce AOE network systematically.

Modern management mode, the public often choose directed graph of description and analysis of the project and the planning process, a project is often divided into several boy, its engineering is activities, English is called the Activity, if the vertices in the weighted directed graph represent events, activities with represented to the edge, while the edge weights of main said this Activity duration, the picture is called AOE network. Basically, AOE network exist the following features: (1) after the event a vertex, will produce since the vertex of the directed edges represent the related activities; (2) complete into some point to the edge on behalf of the activity, the vertices represent event occurs. Can be seen from figure, (1) (5) each engineering events respectively, and the overall engineering since the time required to produce to the end of the shortest is events begin to end the longest path of value, usually the longest path is called critical path. From figure 1, you can see, the longest path of completion of the project since (1), (2), (3), (5), total is $310 \mathrm{~d}$, the path is the critical path of figure 1 . To make a clearer understanding of the critical path and application, the research introduces a few terms about the critical path:

(1) make clear early end time. Activities or decorate adornment, for example, is the earliest start time (1)to(4)the longest path values, $40+120+60=220 \mathrm{~d}$; (2) as early as the end of time, English abbreviation for EF, that is to say, the earliest activities start time and end time is mainly composed of activity time limit for a project together. End of the activity or decorate adornment, for example, the earliest time of $80+220=300 \mathrm{~d}$; (3) the latest start time, English abbreviation for LS. That is to say, the activities will not affect the status of the project completion time can start time at the latest, for example, activities or decorate adornment start time for the latest $310-80=80 \mathrm{~d}$; (4) at the latest end time, English abbreviation for LF. That is, an activity does not affect the overall project completion time on the basis of the latest finish time, for example, or decorating decoration engineering end at the latest time of $310 \mathrm{~d}$; (5) Total time difference, abbreviations for TFt. That is to say, in does not affect the overall project based on the maximum time floating; (6) free jet lag, abbreviations for the FF. [3] That is to say, in does not affect the time after a work situation.

Through the above analysis and discussion, the critical path of features include the following: (1) the critical path of activities consumed time for project time limit for a project as a whole has a decisive role, and the critical path activities time is needed for the project construction period; (2) all activities in the key activities is the critical path and its delay any activity will affect the project completion time; (3) the critical path of time consumption is to be able to complete the amount of time the minimum, shortening the critical path time lead to directly to shorten project period, also will delay the project total time limit for a project at the same time, however, lead to non-critical 
path activities needed to run time shortened, will not affect the project completion time; (4) the critical path activities minimum value for a total time difference, actually consumed during the change of time will lead to the change of the critical path; (5) can exist at the same time the critical path, the same amount of time spent, so that it can end the total time limit for a project.

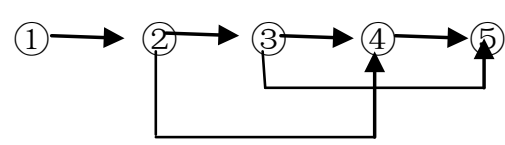

Figure 1. Criticial paths analysis

Note: (1) $\rightarrow$ (2) belong to the basic engineering: $60 \mathrm{~d}$; (3) $\rightarrow$ (4) belong to the equipment installation: $40 \mathrm{~d}$; (2) $\rightarrow$ (3) belong to the principal part of the project: $120 \mathrm{~d}$; (4) $\rightarrow$ (5)belong to decorate device: 80 d.

Basically, critical path itself is relative, or changing development, after choosing related technology organization measures, may convert the critical path for the non-critical path, on the other hand, non-critical path into the possibility of the critical path.

\section{Effective application of the critical path in the construction project management}

Relative to a single project, only the project after the Internet activity within it the longest or the longest, will complete the project, the route is the critical path, the longest activities organized by the critical path of activities is called the critical activities. [4]Usual practice mainly includes: (1) the exist within the project activities as time property of a node, since the project starting point to end point spread arrangement; (2) through the tight direction line will exist different nodes marked correlation with tight activities before and after the activities to ensure that it can become the direction of the Internet figure; (3) through the reverse method or the driving method to different activities in the earliest start time and end time the latest and most late the earliest start time and end time calculation, at the same time for different activity time is calculated; (4) all the time is negative or zero activity related to find out the route, that is the key route; (5) will be accurate critical path, this is the Internet provide restraint conditions optimization.

Prepare the Internet plan basic idea is: in the engineering project management work in a large Internet figure inside to find the critical path, at the same time priority allocation of different resources, key activities and their potential for mining, choose the right way, for shortening the time required. On non-critical activity, however, does not affect the project, on the basis of the overall completion time, and will check goods and resources such as spot checks out, and as well as applications of the critical path, thus shortening the time limit for a project, the purpose of effectively make full use of resources, in the process of execution file, should be priority right, effective scheduling and control key activities, workers should be in accordance with the plan of the proposed requirements, etc for the allocation of resources, the project schedule and cost reduction by synthetically considering all kinds of related target, comprehensive optimization of large Internet figure, finally to the activity plan to be clear.

In the critical path of actual progress significantly ahead of schedule, if you don't set the time limit for a project in advance, then you should choose to have bigger occupancy of resources or high direct costs of subsequent key work, and their duration shall be appropriately extended, thus saving project cost or reduce the intensity of resources, in the case of a clear plan ahead of schedule, must put the plan is not yet complete link as a new plan, and the key work related to determine the 
duration, according to the new plan to implement. [5]Choose to organize the implementation of the scheme, to make full use of the non-critical activities always lag, reasonable increase working time, reasonable use worker to work overtime, add other resources and the shift of technical force, objects, people and money reasonable allocation of resources, so as to largely reduce the time used key activities. Priority arrangement, carried out on the key activities required resources by non-critical activity time, stagger the other activities on time, thus leveling resources boom.

\section{Design and implementation of engineering construction project management system based on the critical path}

The key, the key path not at this point of scarce resources to conduct a comprehensive solution, and as the load and the technical requirements for resources up, need shrinking time cycle, this problem become more prominent in recent years. To make the critical path to complete, and the increasing construction engineering project management time critical chain project management, gradually been recognized and accepted by public.

\subsection{The system overall structure}

Starting from the engineering construction project management system design requirements, design system by using B/S software structure system, to ensure that the design of the system can conform to the actual application. System software design, the system can be divided into data communication, data interface layer and application layer, data communication, can gather relevant data and information engineering construction site, and then with the transmission of information network technology, the data in the data interface layer of information to the system, the system of the program to evaluate the data information, and to develop a project management decisions, and then put the specific project management decision command by the application layer to convey to the client. The system structure of the critical path is as follows: as shown in figure 2:

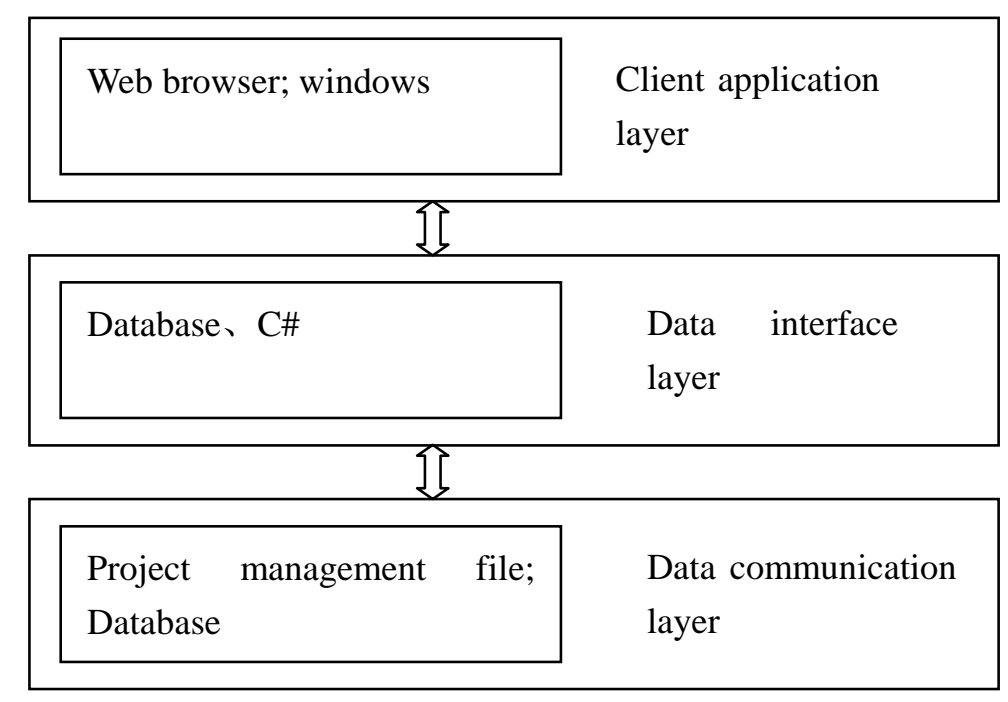

Figure 2 Structure diagram of the system

For the design of engineering construction project management system, the application of B/S software structure system, the system is divided into several layers, and each layer is divided into several functional modules, it is advantageous for the use of modular design to realize system function, can make the system run efficiently, and can guarantee the security of the data in the system. 


\subsection{System function design}

According to the design of engineering construction project management system, the system function design, need to be able to according to the requirements of practical engineering construction project management, in view of the current construction project for systematic and informatization of project management.[6] Therefore, in the system, including quality testing, project management and system maintenance function, make sure you are able to automation of the engineering construction quality inspection, and system evaluation of some unreasonable data exist in the process of engineering construction, and carries on the statistical analysis of the data, so as to develop practical and feasible project management decisions.

In system design, the quality testing purpose, is a review about the quality of the project of specimen, the implementation of engineering construction project management data collection work, and can also be collected the data stored in the database of the system, and is convenient to maintain data query.

System of engineering management section, the purpose in a timely manner to the collected data were analyzed, and the project management and can dig out the useful data, to ensure that can be designed according to the data calculated the optimal project schedule, cost control plan, and will be input to the system of project decision-making in the user interface, and operability of the system.

Similarly, in the system design, also have system maintenance function, the purpose of this function is to construction project data information in the system and the system page information, the system hardware equipment maintenance management, to ensure that the system can run normally.

\section{Summary}

To sum up, the application of the critical path assist construction engineering project to a great extent, especially provide a graphical display for the construction project and priority activities. The quantitative information provide important research basis for clear organization risks, project delay risk, resource risk and risk management.

\section{References}

[1] Tao Zunhai. Application of project management critical path method in the communication engineering project management [J]. Journal of information and communication, 2016.

[2] Yang Lianshan. Whole life cycle integrated management research based on the information platform of large construction project [D]. Shandong Construction University, 2015.

[3] Liao Jian. B measurement automation system for power supply bureau construction project quality and schedule management research [D]. North China electric power university, 2014.

[4] Aiqing. MouPing art of yu ying middle school teaching building construction project progress management research [D]. China ocean university, 2015.

[5] Liujian. The critical path method in project management in communication engineering, the application of project management [D]. Beijing University of posts and telecommunications, 2010.

[6] Wang Junjun. Schedule management in shaanxi digital television source beyond the backup project application [D]. Xi 'an university of electronic science and technology, 2014. 